\title{
Integrated economic and climate projections for impact assessment
}

\author{
Sergey Paltsev • Erwan Monier • Jeffery Scott • \\ Andrei Sokolov • John Reilly
}

Received: 31 January 2013 / Accepted: 22 August 2013 / Published online: 8 October 2013

(C) The Author(s) 2013. This article is published with open access at Springerlink.com

\begin{abstract}
We designed scenarios for impact assessment that explicitly address policy choices and uncertainty in climate response. Economic projections and the resulting greenhouse gas emissions for the "no climate policy" scenario and two stabilization scenarios: at $4.5 \mathrm{~W} / \mathrm{m}^{2}$ and $3.7 \mathrm{~W} / \mathrm{m}^{2}$ by 2100 are provided. They can be used for a broader climate impact assessment for the US and other regions, with the goal of making it possible to provide a more consistent picture of climate impacts, and how those impacts depend on uncertainty in climate system response and policy choices. The long-term risks, beyond 2050, of climate change can be strongly influenced by policy choices. In the nearer term, the climate we will observe is hard to influence with policy, and what we actually see will be strongly influenced by natural variability and the earth system response to existing greenhouse gases. In the end, the nature of the system is that a strong effect of policy, especially directed toward long-lived GHGs, will lag by 30 to 40 years its implementation.
\end{abstract}

\section{Introduction}

The evidence that the climate is changing and that human activities are responsible has been confirmed by the Intergovernmental Panel on Climate Change (IPCC 2007c) and by the US National Academy of Sciences (National Research Council 2011). Attention has turned to how likely future climate change might affect the economy and natural ecosystems. The US government has adopted a "social cost of carbon" concept for regulatory proceedings on greenhouse gas mitigation, based on a measure of damage caused by climate change (IWGSCC 2010; Marten et al. 2013). While there is hope of avoiding climate change - the international community has set the goal of keeping warming to less than $2{ }^{\circ} \mathrm{C}$ above

This article is part of a Special Issue on "A Multi-Model Framework to Achieve Consistent Evaluation of Climate Change Impacts in the United States" edited by Jeremy Martinich, John Reilly, Stephanie Waldhoff, Marcus Sarofim, and James McFarland.

Sergey Paltsev and Erwan Monier wish to be considered as joint first authors.

Electronic supplementary material The online version of this article (doi:10.1007/s10584-013-0892-3) contains supplementary material, which is available to authorized users.

S. Paltsev $(\bowtie) \cdot$ E. Monier $\cdot$ J. Scott $\cdot$ A. Sokolov $\cdot$ J. Reilly

The MIT Joint Program on the Science and Policy of Global Change, Massachusetts Institute of

Technology, Cambridge, MA 02139, USA

e-mail: paltsev@mit.edu 
preindustrial - even if that goal is achieved the world and the US would see on the order of another $1.2^{\circ} \mathrm{C}$ of warming over the next several decades. Given the challenge of achieving such a goal and the lack of progress in developing policies that would likely be needed to achieve it, the world may well experience considerably more warming. Beyond just understanding the potential impacts of climate change on the US for a given scenario, one may be interested in better understanding the benefits of a mitigation strategy: that is how much disruption is avoided for a given mitigation scenario compared with doing nothing or much less mitigation. To answer these questions we need an integrated approach to economic and climate scenario design so that there is a clear relationship between a specific population and economic growth scenario, the resultant emissions and climate outcomes, and back again to the impacts on an economic scenario at least approximately consistent with that driving the emissions scenario.

In this paper we lay out the construction of such a set of scenarios that form the basis for additional analyses of climate impacts. In particular, the scenarios are used for climate change impacts in the US as part of the Climate Impacts and Risk Analysis (CIRA) project (see an overview paper by Waldhoff et al. 2013, in this issue). The scenarios are constructed using the MIT Integrated Earth System Model (IGSM) version 2.3 (Dutkiewicz et al. 2005; Sokolov et al. 2005). A fully integrated approach would include climate impact and adaptation feedbacks on the economy (see e.g., Reilly et al. 2012, for scenarios with the feedbacks and Reilly et al. 2013, for an approach for valuing impacts) so that, in principle, those feedbacks might affect the level of energy, land use, and industrial activity and thus the emissions of greenhouse gases themselves, but that was beyond this exercise.

It is useful to compare very briefly with what has gone before. On the one side, there are models such as DICE (Nordhaus 2008), FUND (Anthoff and Tol 2009), and PAGE (Hope 2013) that attempt a full integration where the overall level of the economy is jointly determined by conventional macroeconomic factors such as labor productivity growth, savings and investment, costs of mitigating greenhouse gases and the damage/adaptation costs related to climate change itself. The goal of these models is often to estimate an "optimal" emissions control path where the marginal social cost of mitigation is equal to the marginal social damage cost of climate change. However, to accomplish this feat, typically the mitigation costs and the damage costs are estimated as a reduced form functions, and so details such as whether warming would change heating demands or land use and thus emissions are omitted. Damage functions are often derived from a meta-analysis of the literature. In this formulation damages are often simply a single dollar value with no trace back to whether they are due to reduced crop yields in region $a$ and increased air conditioning in region $b$. At the other end of the spectrum are impact and adaptation studies, reviewed extensively by the IPCC working group II (IPCC 2007a), that are the basis of these meta-analyses. These are often highly detailed, but may be focused on a single region, and based on one or a few climate scenarios that differ widely among the studies because of inherent differences in climate models as well as different economic and emissions scenarios. Emissions vary because of different economic growth and technology assumptions as well as different assumptions about policy. Meta-analyses often summarize the climate change scenario by a single indicator, global mean surface temperature increase, ignoring other patterns of change that may be important. While useful for many purposes, the mix of different reasons for different climate scenarios makes it difficult to trace back and conclude that Policy A leads to damages of X, and more stringent policy B leads to damages of $\mathrm{Y}$, and so the benefits of taking the more stringent policy are $\mathrm{X}$ minus $\mathrm{Y}$. The goal of the scenario development exercise developed here is to allow such a calculation while also including considerable detail on each impact sector. The scenarios presented here are part of a multi- 
model project to achieve consistent evaluation of climate change impacts in the US (Waldhoff et al. 2013).

\section{Description of the modeling framework}

The MIT Integrated Global System Model version 2.3 (IGSM2.3) is an integrated assessment model that couples a human activity model to a fully coupled earth system model of intermediate complexity that allows simulation of critical feedbacks among its various components, including the atmosphere, ocean, land and urban processes. The earth system component of the IGSM includes a two-dimensional zonally averaged statistical dynamical representation of the atmosphere, a three-dimensional dynamical ocean component with a thermodynamic sea-ice model and an ocean carbon cycle (Dutkiewicz et al. 2005, 2009) and a Global Land Systems (GLS, Schlosser et al. 2007) that represents terrestrial water, energy and ecosystem processes, including terrestrial carbon storage and the net flux of carbon dioxide, methane and nitrous oxide from terrestrial ecosystems. The IGSM2.3 also includes an urban air chemistry model (Mayer et al. 2000) and a detailed global scale zonal-mean chemistry model (Wang et al. 1998) that considers the chemical fate of 33 species including greenhouse gases and aerosols. Finally, the human systems component of the IGSM is the MIT Emissions Predictions and Policy Analysis (EPPA) model (Paltsev et al. 2005), which provides projections of world economic development and emissions over 16 global regions along with analysis of proposed emissions control measures.

EPPA is a recursive-dynamic multiregional general equilibrium model of the world economy, which is built on the Global Trade Analysis Project (GTAP) dataset of the world economic activity augmented by data on the emissions of greenhouse gases, aerosols and other relevant species, and details of selected economic sectors. The model projects economic variables (gross domestic product, energy use, sectoral output, consumption, etc.) and emissions of greenhouse gases (CO2, CH4, N2O, HFCs, PFCs and SF6) and other air pollutants (CO, VOC, NOx, SO2, $\mathrm{NH} 3$, black carbon and organic carbon) from combustion of carbon-based fuels, industrial processes, waste handling and agricultural activities (see Waugh et al. 2011, for emission inventory sources). The model identifies sectors that produce and convert energy, industrial sectors that use energy and produce other goods and services, and the various sectors that consume goods and services (including both energy and non-energy). The model covers all economic activities and tracks domestic use and international trade. Energy production and conversion sectors include coal, oil, and gas production, petroleum refining, and an extensive set of alternative low-carbon and carbon-free generation technologies.

A major feature of the IGSM is the flexibility to vary key climate parameters controlling the climate response: the climate sensitivity, ocean heat uptake rate and net aerosol forcing. The IGSM is also computationally efficient and thus particularly adapted to conduct sensitivity experiments like estimating probability distribution functions of climate parameters using optimal fingerprint diagnostics (Forest et al. 2008) or deriving probabilistic projections of 21 st century climate change under varying emissions scenarios and climate parameters (Sokolov et al. 2009; Webster et al. 2012). The IGSM has also been used to run several-millenia-long simulations (Eby et al. 2012; Zickfeld et al. 2013).

Because the atmospheric component of the IGSM is two-dimensional (zonally averaged), regional climate cannot be directly resolved. To simulate regional climate change, two methods have been applied. First, the IGSM-CAM framework (Monier et al. 2013a) links the IGSM to the National Center for Atmospheric Research (NCAR) Community Atmosphere Model (CAM). Secondly, a pattern scaling method extends the latitudinal projections 
of the IGSM 2-D zonal-mean atmosphere by applying longitudinally resolved patterns from observations, and from climate-model projections (Schlosser et al. 2012). The companion paper by Monier et al. (2013b) describes both a method and presents a matrix of simulations to investigate regional climate change uncertainty in the US.

\section{Scenario design}

Scenario design is a challenge because of the desire to span a wide range of possible outcomes while keeping the number of scenarios to a manageable level. A full uncertainty analysis would sample from uncertain economic/technology and climate parameter inputs. Policy could be addressed as an additional uncertain variable where estimates of the likelihood of policy occurring at different times and stringencies would be necessarily a subjective judgment. The alternative, as in Webster et al. (2012), is to choose multiple "certain" policy scenarios, and produce a large ensemble of runs for each where the different ensemble members represent uncertainty in non-policy related economic/technology and climate parameters. A typical single large ensemble that is able to span the likely range of outcomes may include 400 members. If, then, three separate policy scenarios are examined the total number of scenarios would be 1200 .

The broader study design envisioned here was that a variety of analytical teams would use the scenarios for impact assessment. While this study design has the advantage of bringing in more highly resolved models of specific sectors there are some tradeoffs. One is that often the impact analysis approach requires considerable effort to set up each scenario, or the impact models themselves are computationally intensive, thus realistically these teams were likely to be able to consider only a few to a dozen scenarios. Another limitation is that it precludes a full integration and feedbacks. We thus considered 3 policy scenarios and 4 scenarios to capture uncertainty in climate response resulting in 12 core simulations with the IGSM. The scenarios are then used by other modeling groups to provide a consistent evaluation of climate change impacts (see Waldhoff et al. 2013, for an overview).

\subsection{Policy design}

Given the potential interest in understanding the benefits of mitigation, we necessarily considered a "no policy" scenario (Reference, or REF) that would then be the basis for comparison of any mitigation scenarios. A set of Representative Concentration Pathway (RCP) scenarios have been developed in support of the Intergovernmental Panel on Climate Change as described in van Vuuren et al. (2011). The RCPs were defined in terms of total radiative forcing from preindustrial emissions of anthropogenic greenhouse substances including both long-lived greenhouse gases (GHGs), aerosols and tropospheric ozone but excluding effects of land cover change, jet contrails, and other smaller contributors. A total of 4 RCPs were defined where radiative forcing would not exceed 2.6, 4.5, 6 and $8.5 \mathrm{~W} / \mathrm{m}^{2}$ by 2100 (i.e., RCP 2.6 does exceed the stated level of forcing at some point, it reaches $2.6 \mathrm{~W} / \mathrm{m}^{2}$ in 2100 ).

Much of the international negotiations are focused on staying below $2{ }^{\circ} \mathrm{C}$ of warming from preindustrial. To have a reasonable chance of staying at that level would require the most stringent RCP2.6. That said there is considerable question as to whether such a target is feasible given the lack of significant progress in developing an international agreement to limit greenhouse gases.

Most analyses that attempt to represent such a scenario either relax the requirement to allow for overshoot with gradual return to the lower level, or require some type of negative 
emission technology. Given the unlikelihood of reaching this goal, we focused on a scenario of stabilization at $4.5 \mathrm{~W} / \mathrm{m}^{2}$ and then constructed a $3.7 \mathrm{~W} / \mathrm{m}^{2}$ scenario, referred to subsequently as POL4.5 and POL3.7, respectively. While not among the RCP family, it might be considered a somewhat more realistic scenario than RCP2.6, and allows a comparison of what is gained from making the extra effort to get from POL4.5 to POL3.7. While there are many issues that arise in estimating an optimal mitigation trajectory (see e.g., Jacoby 2004) such optimality is where the marginal benefit equals the marginal cost. The differences between POL4.5 and POL3.7 provide something closer to a marginal benefit.

In contrast to RCPs, where each scenario is developed by a different modeling group (and as such some aspects of the scenarios are not compatible, such as, for example, land-use emissions), an advantage of our approach is that all scenarios are constructed with a set of consistent interactions between population growth, economic development, energy and land system changes and the resulting emissions of GHGs, aerosols, and air pollutants. In addition, while the scenarios underlying the different RCPs were developed by different models and assumed different baselines, this study not only uses the same model, but also a single baseline.

Another potentially important element of the scenario design is how the policy is implemented. One might hope to represent a realistic policy design, however, actual policies being implemented by countries today are not close to achieving POL3.7 or even POL4.5. For example, Paltsev et al. (2012) estimate that the Copenhagen-Cancun international agreement would lead to about $9.0 \mathrm{~W} / \mathrm{m}^{2}$ by 2100 . Hence current policies provide no guidance for what would be needed to achieve these tighter targets. To have any chance of achieving them the policy measures need to be universal, including essentially all countries, and cover all greenhouse gases. And the policies need to be effective. For example, Clarke et al. (2009) consider several models in an idealized cost-effective mitigation setting and conclude that a delay in participation by developing countries increases the costs and challenges of meeting long-term climate goals.

Other important elements of policy design are which countries bear the cost burden of reducing emissions as well as the timing of emissions reduction. While there are many schemes to distribute the burden, such as per capita emissions targets and the like, these often have relatively perverse equity effects (see e.g., Jacoby et al. 2009). As a result, we chose a simple policy design - a uniform global carbon tax, constant in net present value terms, where each region collects and recycles the revenue internally to its representative agent. Through an iterative procedure we determine the tax rate needed to achieve the target, and we apply the tax to all GHG emissions where Global Warming Potential (GWP) indices adjust the tax level for different greenhouse gases.

Reilly et al. (2012) discuss the thought experiment that allows more stringent climate targets by ideally pricing land carbon, and show the significant trade-offs with this integrated land-use approach when prices for agricultural products rise substantially because of mitigation costs borne by the sector and higher land prices. There are also policy coordination issues of extending a carbon tax to land (Reilly et al. 2012) and competition between energy crops and forest carbon strategies (Wise et al. 2009). Therefore, we exclude $\mathrm{CO}_{2}$ emissions from land-use change from the tax in this study.

This formulation of the tax policy means that each region bears the direct cost of its abatement activities but may benefit or lose from effects transmitted through trade. A uniform global tax that is constant in net present value terms, by equating marginal cost of reduction across space and time would, under some ideal conditions lead to a least-cost solution. However, interaction with other distortions and externalities could mean there are even more efficient solutions, e.g., if tax revenue were used to reduce other distortionary tax rates or there were other benefits of reduced 
conventional pollutants. Similarly, if one designed the tax strategy in consideration of existing energy taxes and policies the economic cost of the policy could be lower. A uniform global tax policy is far more efficient than existing policies because they are highly differentiated among sectors and regions, and often use multiple policy instruments that lead to wide disparities in marginal cost and suffer from leakage.

\subsection{Climate parameter choice}

To represent uncertainty in earth system response to changing concentrations of greenhouse gases and aerosols, the climate sensitivity of the atmospheric model was altered to span the range given by the Intergovernmental Panel on Climate Change (IPCC), with an additional low probability/high risk value. The ocean heat uptake rate in all simulations lies between the mode and the median of the probability distribution obtained with the IGSM using optimal fingerprint diagnostics similar to Forest et al. (2008). This corresponds to an effective vertical eddy diffusivity of $0.5 \mathrm{~cm}^{2} / \mathrm{s}$. The four values of climate sensitivity (CS) considered are 2.0, 3.0, 4.5 and $6.0^{\circ} \mathrm{C}$, which represent respectively the lower bound (CS2.0), best estimate (CS3.0) and upper bound (CS4.5) of climate sensitivity based on the Fourth Assessment Report of the Intergovernmental Panel on Climate Change (IPCC 2007b), and a low probability/high risk climate sensitivity (CS6.0). The associated net aerosol forcing was chosen to ensure a good agreement with the observed climate change over the 20th century. This is achieved based on the marginal posterior probability density function with uniform prior for the climate sensitivity-net aerosol forcing (CS-Fae) parameter space shown in Fig. 1. The net aerosol forcing is chosen to provide the same transient climate response as the median set of parameters of the CS-Fae parameter space. The values are $-0.25 \mathrm{~W} / \mathrm{m}^{2},-0.70 \mathrm{~W} / \mathrm{m}^{2},-0.85 \mathrm{~W} / \mathrm{m}^{2}$ and $-0.95 \mathrm{~W} / \mathrm{m}^{2}$ for, respectively, CS2.0, CS3.0, CS4.5 and CS6.0. While choosing a single value of ocean heat uptake rate instead of sampling all three climate parameters is limiting the representation of the full range of uncertainty in future climate change, it allows for a reasonable

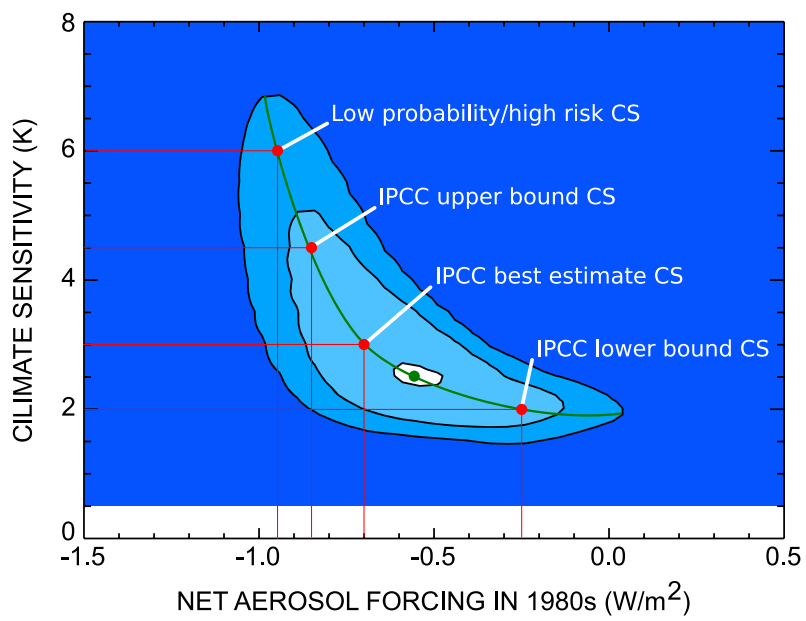

Fig. 1 The marginal posterior probability density function with uniform prior for the climate sensitivity-net aerosol forcing (CS-Fae) parameter space from Forest et al. (2008). The shading denotes rejection regions for a given significance level $-50 \%, 10 \%$ and $1 \%$, light to dark, respectively (Forest et al. 2008). The positions of the red and green dots represent the parameters used in the simulations presented in this study. The green line represents combinations of climate sensitivity and net aerosol forcing leading to the same transient climate response as the median set of parameters (green dot) 
number of simulations to be considered. In addition, if we considered a higher (lower) ocean heat uptake rate, it would require higher (lower) values of climate sensitivity in order to reproduce the observed 20th century, thus resulting in similar future climate change. Due to the correlation between climate parameters imposed by the requirement to match the observed 20th century temperature change, this decrease in the range of uncertainty will be rather small, especially on time scales less than one century considered here.

\section{Economic and energy projections}

In EPPA, key assumptions about population and labor growth interact to endogenously determine the rates of growth in each region and in the world. These assumptions concern: growth in productivity of labor, land and energy; the exhaustible and renewable resource base; technology availability/cost; and policy constraints. More rapid productivity growth leads to higher rates of output, savings, investment and GDP growth. More rapid growth will deplete resources faster and press against available renewable resources and these pressures will retard growth. Policy constraints that limit the use of available fossil resources will also tend to slow growth. However, the version of the model used here does not include any climate and environmental feedbacks on the economy. Given space limitations, we provide a high level overview of the key results. Detailed tables of results for each scenario are provided in the Online Resources (see Online Resource 1 for the list of files).

GDP growth varies by region and policy scenario (Online Resource 1). The U.S. economic growth up to 2035 is based on the EIA Annual Energy Outlook (EIA 2011). In the other regions the 2005-2010 growth is based on historical data and also includes the recent recession, but by 2015 we assume rates of productivity growth similar to the past 30 years (similar assumption is made for the U.S. growth after 2035). Slowing population growth and gradual slowing of labor productivity over time leads to somewhat slower growth in all regions in the second half of the century. Growth is generally more rapid in lower income countries than higher income countries, assuming some catch-up. Growth in POL4.5 is slowed by about $0.2 \%$ to as much as $0.6 \%$ per year depending on the region compared with No Policy. Going from the POL4.5 to POL3.7 cuts another 0.1 to $0.2 \%$. EPPA models international trade, and so solves in market exchange rates. An alternative is to convert GDP to purchasing power parity (PPP). Using PPP would value upward the level of GDP in many of the lower income countries, but would not change the growth rate. Such revaluation would give more weight to lower income countries and so would tend to raise the world average. In later figures we aggregate these regions to include the USA, Other Developed, Other G-20, and Rest of the World. Countries and regions included in these regions are defined in Online Resource 1. The G-20 is the largest 20 economies of the world. Our Other G-20 group - large economies not among the traditional "developed" economies - is an approximation given the level of aggregation in the EPPA model: South Africa, Turkey and Saudi Arabia are among the G-20 but not in our grouping because they are aggregated into other large regions in EPPA. High Income Asia includes Korea and Indonesia, among the G-20, but also several other smaller economies (see Online Resource 1 and Paltsev et al. 2012).

The most important results in terms of effects on climate are global GHG emissions (Fig. 2). Included are $\mathrm{CO}_{2}$ emissions from fossil energy combustion, industry (i.e. primarily cement), and $\mathrm{CH}_{4}, \mathrm{~N}_{2} \mathrm{O}$, PFCs, $\mathrm{HFCs}$, and $\mathrm{SF}_{6}$. $\mathrm{CO}_{2}$ emissions from land are not included in this total but an estimate of global net emissions from human activity is included in the Online Resources. The IGSM has an active terrestrial vegetation model that responds to climate and atmospheric $\mathrm{CO}_{2}$, an active ocean model that takes up $\mathrm{CO}_{2}$, and explicit chemistry, e.g., oxidizes $\mathrm{CH}_{4}$ into $\mathrm{CO}_{2}$. We infer anthropogenic land use emissions given 

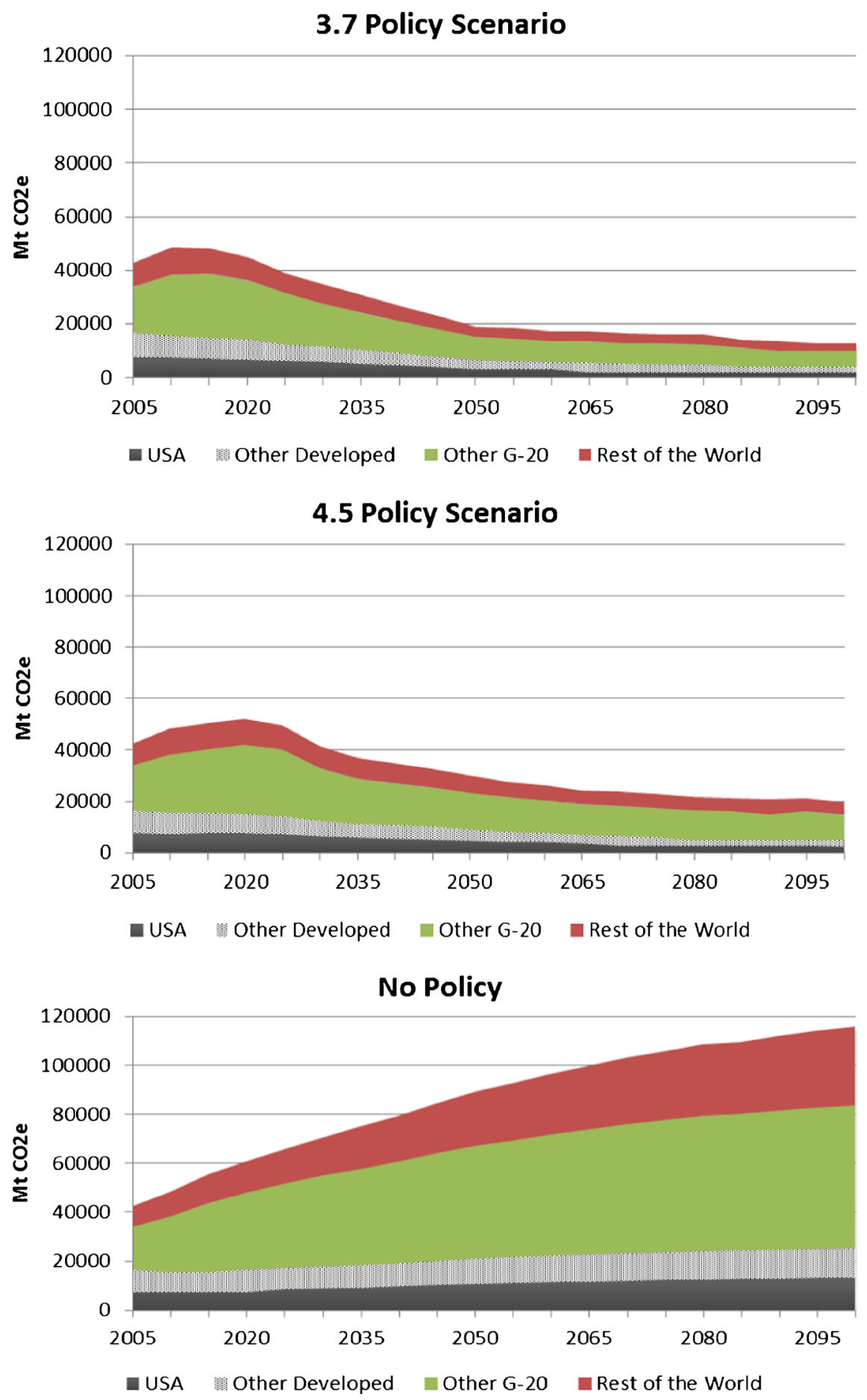

Fig. 2 Anthropogenic emissions: $\mathrm{CO}_{2}$ (fossil and industrial) $\mathrm{CH}_{4}, \mathrm{~N}_{2} \mathrm{O}, \mathrm{HFCs}$, SF6, and PFCs Emissions (Mt of $\mathrm{CO}_{2}$-equivalent). See Online Resource 1 for regions 
historical estimated fossil and industrial emissions, the modeled ocean and terrestrial vegetation response as the additional emissions needed to match the recent trends in observed concentrations. The IGSM also separately models natural sources of $\mathrm{CH}_{4}$ (wetlands) and $\mathrm{N}_{2} \mathrm{O}$ (unfertilized soils), and how such emissions respond to climate change. Amplified natural emissions due to climate change are not included in Fig. 2. However, all of these changes are reflected in estimates of changes in concentrations, radiative forcing and temperature reported in the next section.

Emissions of other substances beyond the "Kyoto" gases are also important for the climate, either because of their direct radiative effect or, indirectly, as the result of atmospheric chemistry processes. EPPA projects emissions of $\mathrm{SO}_{2}, \mathrm{CO}, \mathrm{VOCs}, \mathrm{BC}, \mathrm{OC}$, and $\mathrm{NH}_{3}$. EPPA models multiple sources of each of these substances as both as co-products, with $\mathrm{CO}_{2}$, of the combustion of fossil fuels, and of other activities, many associated with agricultural practices and biomass burning. Coefficients of emissions per unit of activity vary by fuel (oil, coal, gas), by sector and technology, by region, and over time reflecting more attention to pollution reduction by different regions as they advance and develop. For those emissions directly associated with fuel combustion, carbon policy has a strong ancillary effect (mostly beneficial reductions). This is less so for those emissions associated with biomass burning. In our projections (Online Resources) China is often the largest regional source of these pollutants because of its large and rapidly growing energy use, and limited pollution control. The exceptions are $\mathrm{BC}$ and $\mathrm{OC}$ where Africa is the largest source because of biomass burning. In Reference, $\mathrm{SO}_{2}, \mathrm{BC}$, and $\mathrm{OC}$ rise a bit initially but then fall, even though underlying fossil energy consumption is growing because we represent emissions coefficients as falling due to development and pollution (but not climate) policy. Emissions of NOx, CO and VOCs continue to grow, as these have proved more difficult to control, although slower than fossil fuel use. In both POL4.5 and POL3.7, the existence of policies that affect fossil fuel use, and the technologies used to burn it, reduce or further reduce other pollutant emissions. This link is weakest for those pollutants, e.g., $\mathrm{BC}$ and $\mathrm{OC}$, that are dominated by biomass burning, especially related to agricultural practices such as open savannah burning or land clearing.

\section{Global earth system implications}

Figure 3 shows $\mathrm{CO}_{2}$ concentrations and GHG global radiative forcing for the three emissions scenarios along with the SRES (Nakićenović et al. 2000) and RCP scenarios (van Vuuren et al. 2011). Under the reference scenario, the $\mathrm{CO}_{2}$ concentration reaches $830 \mathrm{ppm}$ in 2100 (and $1750 \mathrm{ppm}$ of $\mathrm{CO}_{2}$-equivalent) and the $\mathrm{GHG}$ radiative forcing is $9.7 \mathrm{~W} / \mathrm{m}^{2}$ (total radiative forcing of $10 \mathrm{~W} / \mathrm{m}^{2}$ ). Even though the $\mathrm{CO}_{2}$ concentrations are lower than the RCP8.5 and the SRES A1FI scenarios, the GHG global radiative is larger. That is largely caused by higher emissions (and thus concentrations) of $\mathrm{CH} 4$, both natural and anthropogenic. The large reduction in greenhouse gas concentration and global radiative forcing achieved by the two policies is clear. The implementation of POL4.5 leads to a $\mathrm{CO}_{2}$ concentration of $500 \mathrm{ppm}\left(600 \mathrm{ppm}\right.$ of $\mathrm{CO}_{2}$ equivalent) and a GHG radiative forcing of $4.3 \mathrm{~W} / \mathrm{m}^{2}$ (total radiative forcing of $4.5 \mathrm{~W} / \mathrm{m}^{2}$ ) in 2100. Under POL3.7, the CO2 concentration is $460 \mathrm{ppm}$ ( $500 \mathrm{ppm}$ of $\mathrm{CO}_{2}$-equivalent) in 2100 and the GHG radiative forcing is $3.6 \mathrm{~W} / \mathrm{m}^{2}$ (total radiative forcing of $3.7 \mathrm{~W} / \mathrm{m}^{2}$ ).

Figure 4 shows time series of global mean temperature, precipitation, sea level rise (including thermal expansion and the melting of glaciers, but excluding the melting of ice sheets) and ocean $\mathrm{pH}$ for the 12 core simulations with the IGSM. The difference in emissions scenarios between REF and even the more modest POL4.5 are quite large, and even more so for POL3.7. However, through about 2040 the uncertainty in climate sensitivity tends to dominate the sea 

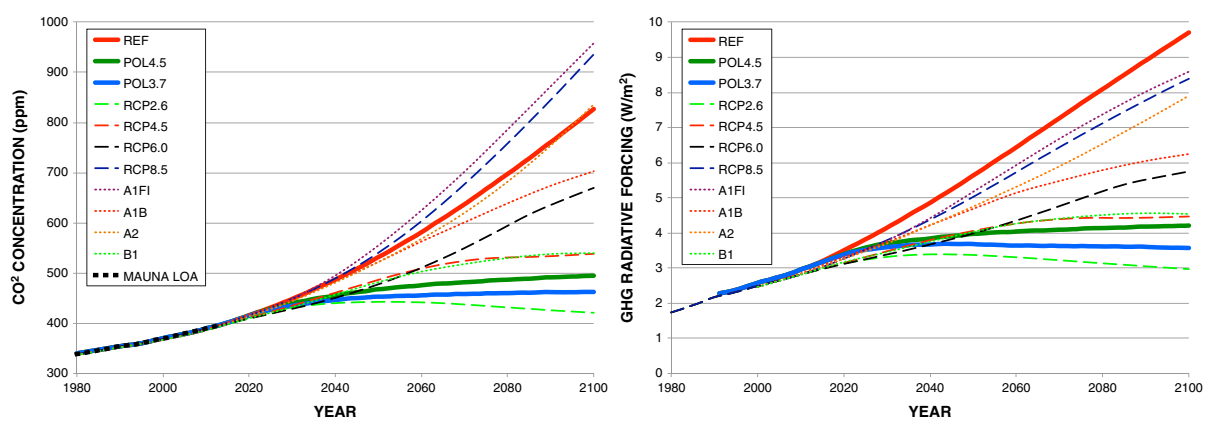

Fig. $3 \mathrm{CO}_{2}$ concentration, in ppm, and greenhouse gases (GHG) radiative forcing, in $\mathrm{W} / \mathrm{m}^{2}$, (including $\mathrm{CO}_{2}$, $\mathrm{CH}_{4}, \mathrm{~N}_{2} \mathrm{O}$, PFCs, SF6, HFCs, CFCs and HCFCs) for the three scenarios presented in this paper, the four RCP scenarios and the SRES scenarios A1FI, A1B, A2 and B1. $\mathrm{CO}_{2}$ concentrations observed at Mauna Loa are also shown until 2012

level rise and changes in temperature and precipitation. That is because emissions cuts of longlived GHGs must accumulate before we see a large effect on various earth system outcomes. On the other hand, ocean $\mathrm{pH}$ is mainly affected by emissions scenarios because the oceans are absorbing about a third of the $\mathrm{CO} 2$ emitted into the atmosphere. As atmospheric $\mathrm{CO} 2$ concentrations increase, oceans become more acidic. After 2040, the policy scenarios begin
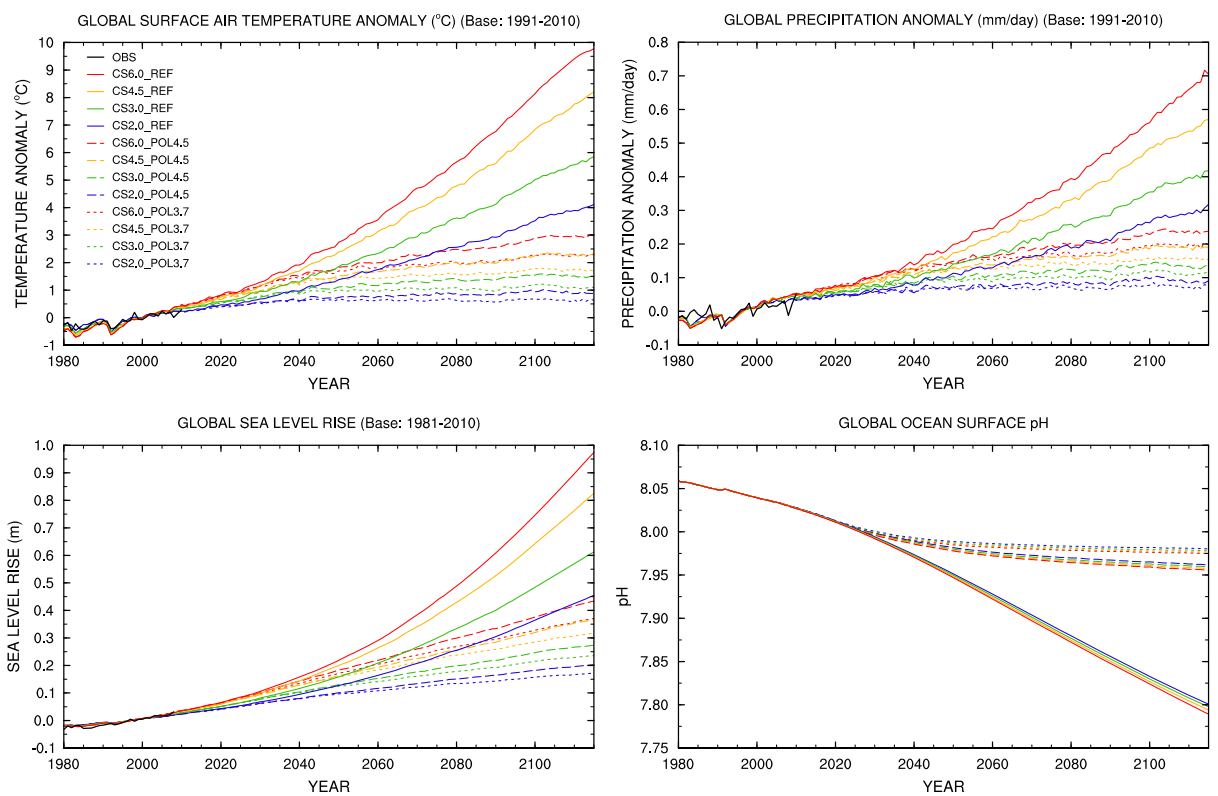

Fig. 4 Time series of global mean surface air temperature and precipitation anomalies from the 1981-2010 base period, sea level rise (including thermal expansion and melting of glaciers, but excluding ice sheets) from the 1981-2010 base period and ocean $\mathrm{pH}$ for the 12 core simulations with the IGSM. The black lines represent observations, the Goddard Institute for Space Studies (GISS) surface temperature (GISTEMP, Hansen et al. 2010), the 20th Century Reanalysis V2 precipitation (Compo et al. 2011) and the Church and White Global Mean Sea Level Reconstruction (Church and White 2011). The blue, green, orange and red lines represent, respectively, the simulations with a climate sensitivity of $2.0,3.0,4.5$ and $6.0^{\circ} \mathrm{C}$. The solid, dashed and dotted lines represent, respectively, the simulations with the reference scenario, stabilization scenario at $4.5 \mathrm{~W} / \mathrm{m}^{2}$ and the stabilization scenario at $3.7 \mathrm{~W} / \mathrm{m}^{2}$ 
to separate from the reference scenario. By 2080, there is clear separation: Even with the lowest climate sensitivity (CS2.0), the temperature in the reference scenario is above that of POL4.5 with the highest climate sensitivity (CS6.0). These scenarios quantify the general conclusion that in the nearer term the future climate will be largely controlled by natural variability and the climate response (the actual climate sensitivity of the earth system). Scientific research combined with the simple unfolding of the climate over the next decades will narrow this outcome. Policy choices will have relatively little effect in the near term, but become the dominant factor by the second half of the century. Of course, this is a receding window; if we don't start to significantly change the current emissions path until 2030 or 2040 , then we will not see a strong effect of those policies until very late in the century.

The reference scenario clearly takes the earth system into dangerous territory, even under the assumption of a low climate sensitivity, with temperature increases by the end of the century ranging from 3.5 to $8.5^{\circ} \mathrm{C}$. Global precipitation increases range from 0.3 to $0.6 \mathrm{~mm} /$ day by 2100. Generally, the simulation with the largest increase in temperature also shows the largest increase in precipitation. Sea level rise, excluding the melting of ice sheets, shows a range of 40 to $80 \mathrm{~cm}$ in 2100 . However, the range of sea level rise is likely underestimated because only one value of ocean heat uptake rate is considered in this study. And even if temperature increases halted where they are at the end of these simulations, gradual warming of the ocean would continue for hundreds of years, and with it continued sea level rise. Finally, global mean ocean $\mathrm{pH}$ decreases to about 7.8 by the end of the simulations, compared to 8.05 during present-day, under the reference scenario. The reduced $\mathrm{pH}$ would strongly affect marine organisms and have economic implications for fisheries (see Lane et al. 2013). Both POL4.5 and POL3.7 greatly reduce these risks, and current uncertainty in climate response dominates the difference in these policies through 2100. Of course, regardless of how uncertainty is resolved, lower GHG concentrations will lead to less climate change.

\section{Conclusions}

We designed scenarios for impact assessment that explicitly address policy choices and uncertainty in climate response. These were designed as part of a broader climate impact assessment for the US, with the goal of making it possible to provide a more consistent picture of climate impacts on the US, and how those impacts depend on uncertainty in climate system response and policy choices. We stressed a difference in outcomes between one policy scenario (POL4.5) and a somewhat more stringent one (POL3.7), particularly because the POL3.7 scenario is not among the RCPs, yet is likely a more plausible policy target than the RCP2.6 scenario. Clearly, the long-term risks, beyond 2050, of climate change can be strongly influenced by policy choices. In the nearer term, the climate we will observe is hard to influence with policy, and what we actually see will be strongly influenced by natural variability and the earth system response to existing greenhouse gases. In the end, the nature of the system is that a strong effect caused by policy, especially policy directed toward long-lived GHGs, will lag 30 to 40 years behind its implementation. Hence if we delay and make a choice only when climate sensitivity is revealed, we may find we are on a path that will take us into dangerous territory with little we can do to stop it, short of geoengineering.

Acknowledgments This work was partially funded by the US Environmental Protection Agency under Cooperative Agreement \#XA-83600001. The Integrated Global System Model (IGSM) and its economic component, the MIT Emissions Predictions and Policy Analysis (EPPA) model, used in this analysis is supported by a consortium of government, industry, and foundation sponsors of the MIT Joint Program on the 
Science and Policy of Global Change. For a complete list of sponsors, see: http://globalchange.mit.edu. The 20th Century Reanalysis V2 data was provided by the NOAA/OAR/ESRL PSD, Boulder, Colorado, USA, from their Web site at http://www.esrl.noaa.gov/psd/.

Open Access This article is distributed under the terms of the Creative Commons Attribution License which permits any use, distribution, and reproduction in any medium, provided the original author(s) and the source are credited.

\section{References}

Anthoff D, Tol R (2009) The impact of climate change on the balanced growth equivalent: an application of FUND. Environ Res Econ 43:351-367

Church JA, White NJ (2011) Sea-level rise from the late 19th to the early 21st century. Surv Geophys 32(4):585-602

Clarke L, Edmonds J, Krey V, Richels R, Rose S, Tavoni M (2009) International climate policy architectures: overview of the EMF 22 International Scenarios. Energy Econ 31(S2):S64-S81

Compo G, Whitaker J, Sardeshmukh P et al (2011) The twentieth century reanalysis project. Quart J Roy Meteor Soc 137(654):1-28

Dutkiewicz S, Sokolov AP, Scott J, Stone P (2005) A three-dimensional ocean-seaice-carbon cycle model and its coupling to a two-dimensional atmospheric model: uses in climate change studies. Report 122, MIT Joint Program on the Science and Policy of Global Change

Dutkiewicz S, Follows M, Bragg J (2009) Modeling the coupling of ocean ecology and biogeochemistry. Global Biogeochem Cycles 23(4):GB4017

Eby M, Weaver AJ, Alexander K, Zickfeld K et al (2012) Historical and idealized climate model experiments: an intercomparison of Earth system models of intermediate complexity. Clim Past 9:1111-1140

EIA (2011) Annual Energy Outlook 2011, U.S. Energy Information Administration

Forest C, Stone P, Sokolov A (2008) Constraining climate model parameters from observed 20th century changes. Tellus $60 \mathrm{~A}(5): 911-920$

Hansen J, Ruedy R, Sato M, Lo K (2010) Global surface temperature change. Rev Geophys 48(4):RG4004

Hope C (2013) Critical issues for the calculation of the social cost of CO2: why the estimates from PAGE09 are higher than those from PAGE2002. Clim Chang 117:531-543

IPCC (2007a) In: Parry ML, Canziani OF, Palutikoff JP, van der Linden PJ, Hanson CE (eds) Climate change 2007: impacts, adaptation, and vulnerability. Contribution of working group ii to the fourth assessment report of the intergovernmental panel on climate change. Cambridge University Press, Cambridge

IPCC (2007b) In: Pachauri RK, Reisinger A (eds) Climate change 2007: synthesis report. Contribution of Working Groups I, II and III to the Fourth Assessment Report of the Intergovernmental Panel on Climate Change. Cambridge University Press, Cambridge, $104 \mathrm{pp}$

IPCC (2007c) In: Solomon S (ed) Climate change 2007: the physical science basis. Contribution of Working Group I to the Fourth Assessment Report of the Intergovernmental Panel on Climate Change. Cambridge University Press, Cambridge

IWGSCC (2010) Technical support document: social cost of carbon for regulatory impact analysis under executive order 12866. Interagency Working Group on Social Cost of Carbon. United States Government, Washington

Jacoby HD (2004) Informing climate policy given incommensurable benefits estimates. Glob Environ Chang Part A 14(3):287-279

Jacoby HD, Babiker MH, Paltsev S, Reilly JM (2009) Sharing the burden of GHG reductions. In: Aldy J, Stavins R (eds) Post-Kyoto international climate policy. Cambridge University Press, Cambridge, pp 753-785

Lane D et al (2013) Climate change impacts on freshwater fish, coral reefs, and related ecosystem services, climatic change, submitted, this issue

Marten AL, Kopp RE, Shouse KC et al (2013) Improving the assessment and valuation of climate change impacts for policy and regulatory analysis. Clim Chang 117:433-438

Mayer M, Wang C, Webster M, Prinn R (2000) Linking local air pollution to globalchemistry and climate. J Geophys Res 105(D18):22869-22896

Monier E, Scott JR, Sokolov AP, Forest CE, Schlosser CA (2013a) An integrated assessment modelling framework for uncertainty studies in global and regional climate change: the MIT IGSM-CAM (version 1.0). Geosci Model Dev Discuss 6:2213-2248 
Monier E, Gao X, Scott J, Sokolov A, Schlosser A (2013b) A framework for modeling uncertainty in regional climate change, Climatic Change, submitted, this issue; see also MIT Joint Program on the Science and Policy of Global Change Report 244. (http://globalchange.mit.edu/files/document/MITJPSPGCRpt244.pdf)

Nakićenović N, Alcamo J, Davis G, de Vries B, Fenhann J, Gaffin S, Gregory K, Grübler A, Jung TY, Kram T, La Rovere EL, Michaelis L, Mori S, Morita T, Pepper W, Pitcher H, Price L, Riahi K, Roehrl A, Rogner H-H, Sankovski A, Schlesinger M, Shukla P, Smith S, Swart R, van Rooijen S, Victor N, Dadi Z (2000) IPCC special report on emissions scenarios. Cambridge University Press, Cambridge

Nordhaus WD (2008) A question of balance: weighing the options on global warming policies. Yale University Press, New Haven

National Research Council (2011) America's climate choices, national academy of sciences. Board on Atmospheric Sciences and Climate (BASC), Committee on America's Climate Choices, The National Academies Press, Washington

Paltsev S, Reilly JM, Jacoby HD, Eckaus RS, McFarland J Sarofim M, Asadoorian M, Babiker M (2005) The MIT Emissions Prediction and Policy Analysis (EPPA) Model: Version 4. MIT Joint Program Report 125, August, 72 p. (http://globalchange.mit.edu/files/document/MITJPSPGCRpt125.pdf)

Paltsev S, Dutkiewicz S, Ekstrom V, Forest CE, Gurgel A, Huang J, Karplus V, Monier E, Reilly J, Scott JR, Slinn A, Smith-Grieco T, Sokolov AP (2012) 2012 Climate and Energy Outlook, MIT Joint Program Report Special Report, (http://globalchange.mit.edu/research/publications/other/special/2012Outlook)

Reilly J, Melillo J, Cai Y, Kicklighter D, Gurgel A, Paltsev S, Cronin T, Sokolov A, Schlosser CA (2012) Using land to mitigate climate change: hitting the target, recognizing the trade-offs. Environ Sci Technol 46(11):5672-5679

Reilly J, Paltsev S, Strzepek K, Selin N, Cai Y, Nam K, Monier E, Dutkiewicz S, Scott J, Webster M, Sokolov A (2013) Valuing climate impacts in integrated assessment models: the MIT IGSM. Clim Chang 117(3):561-573

Schlosser CA, Kicklighter D, Sokolov A (2007) A global land system framework for integrated climatechange assessments. MIT Joint Program on the Science and Policy of Global Change, Report 147 (http:// globalchange.mit.edu/files/document/MITJPSPGCRpt147.pdf)

Schlosser CA, Gao X, Strzepek K, Sokolov A, Forest CE, Awadalla S, Farmer W (2012) Quantifying the likelihood of regional climate change: a hybridized approach. J Clim 26(10):3394-3414

Sokolov A, Schlosser CA, Dutkiewicz S, Paltsev S, Kicklighter D, Jacoby H, Prinn R, Forest C, Reilly J, Wang C, et al. (2005) MIT integrated global system model (IGSM) version 2: model description and baseline evaluation. Rep. 124, MIT Joint Program on the Science and Policy of Global Change (http:// globalchange.mit.edu/files/document/MITJPSPGCRpt124.pdf)

Sokolov A, Stone P, Forest C, Prinn R, Sarofim M, Webster M, Paltsev S, Schlosser CA, Kicklighter D, Dutkiewicz S et al (2009) Probabilistic forecast for twenty-first-century climate based on uncertainties in emissions (Without Policy) and climate parameters. J Clim 22(19):5175-5204

van Vuuren D, Edmonds J, Kainuma M, Riahi K, Weyant J (2011) A special issue on the RCPs. Clim Chang $109(1-2): 1-4$

Waldhoff S, Martinich J, Sarofim M, DeAngelo B, McFarland J, Jantarasami L, Shouse K, Crimmins A, Li J (2013) Overview of the Special Issue: a multi-model framework to achieve consistent evaluation of climate change impacts in the United States. Climatic Change submitted, this issue

Wang C, Prinn R, Sokolov A (1998) A global interactive chemistry and climate model-formulation and testing. J Geophys Res 103:3399-3417

Waugh C, Paltsev S, Selin N, Reilly J, Morris J, Sarofim M (2011) Emission inventory for non-CO2 greenhouse gases and air pollutants in EPPA 5, technical note 12, MIT Joint Program on the Science and Policy of Global Change (http://globalchange.mit.edu/files/document/MITJPSPGCTechNote12.pdf)

Webster M, Sokolov AP, Reilly JM, Forest CE, Paltsev S, Schlosser CA, Wang C, Kicklighter D, Sarofim M, Melillo J, Prinn RG, Jacoby HD (2012) Analysis of climate policy targets under uncertainty. Clim Chang 112(3-4):569-583

Wise M, Calvin K, Thomson A et al (2009) Implications of limiting CO2 concentrations for land use and energy. Science 324:1183-1186

Zickfeld K, Eby M, Weaver AJ et al (2013) Long-term climate change commitment and reversibility: an EMIC intercomparison. J. Clim. doi:10.1175/JCLI-D-12-00584.1 